\title{
The Promise of Turning Induced Deformation Process for Synthesizing Magnesium Based Materials with Superior Mechanical Response
}

\author{
Michael Johanes and Manoj Gupta * (D) \\ Department of Mechanical Engineering, 9 Engineering Drive 1, National University of Singapore, \\ Singapore 117575, Singapore; michael.johanes@u.nus.edu \\ * Correspondence: mpegm@nus.edu.sg; Tel.: +65-6516-6358
}

check for updates

Citation: Johanes, M.; Gupta, M. The Promise of Turning Induced Deformation Process for Synthesizing Magnesium Based Materials with Superior Mechanical Response. Technologies 2021, 9, 69. https:// doi.org/10.3390/technologies 9040069

Academic Editor: Paolo Veronesi

Received: 25 August 2021

Accepted: 17 September 2021

Published: 22 September 2021

Publisher's Note: MDPI stays neutral with regard to jurisdictional claims in published maps and institutional affiliations.

Copyright: (c) 2021 by the authors. Licensee MDPI, Basel, Switzerland. This article is an open access article distributed under the terms and conditions of the Creative Commons Attribution (CC BY) license (https:/ / creativecommons.org/licenses/by/ $4.0 /)$.

\begin{abstract}
In recent times, an alternative synthesis pathway involving severe plastic deformation for Mg-based materials has been explored involving the generation of turnings according to a set of machining parameters and cold compaction into billets followed by hot extrusion. This is known as the turning induced deformation (TID) method and has shown potential to alter the properties of resulting Mg-based materials for the better, not to mention economic benefits arising from this processing method. This work summarizes exploratory efforts involving this method for synthesis of Mg-based materials. The TID method resulted in overall superior properties compared to conventional processing methods, while two distinct parameters (high depth of cut and low cutting speed) were found to have significant positive influence on the final material properties, and as such are considered to be suitable basis on which further exploratory work in this field may be conducted.
\end{abstract}

Keywords: magnesium; turning; processing; strength; recycling; deformation

\section{Introduction}

As a lightweight structural metal, magnesium $(\mathrm{Mg})$ and its alloys have found applications in the engineering and biomedical industries [1,2]. Mg-based materials are also very suitable for machining [3]. Advantages in this regard include lower power consumption, longer tool life, and better surface finishes for a given set of conditions. For these reasons, machining is a commonly employed processing method for Mg-based materials [4].

However, the machining process (which is subtractive in nature) invariably results in generation of swarf (turnings). These would normally then be discarded or re-melted to recycle the magnesium, which presents additional energy costs and material wastage $[5,6]$. Thus, it is of economic importance that any possible energy and material savings be introduced into the process flow.

Given that primary production of $\mathrm{Mg}$ consumes a minimum of $35 \mathrm{kWh} / \mathrm{kg}$ while remelting of $\mathrm{Mg}$ scrap/turnings only consumes $3 \mathrm{kWh} / \mathrm{kg}$ [7], the already-large energy savings potential of recycling $\mathrm{Mg}$ can be increased even further by usage of direct recycling which does not need any form of remelting, with implications of even larger energy savings considering global primary production of $\mathrm{Mg}$ in 2020 exceeded 1 million metric tons [8]. With regards to automobiles, it was also found that a $10 \%$ reduction in weight resulted in $5.5 \%$ better fuel economy [9], further providing justification in utilization of $\mathrm{Mg}$ materials as structural members not just for their engineering properties, but also associated cost and energy savings in use and recycling.

Swarf recycling is a well-explored concept, and thus far, efforts into recycling of $\mathrm{Mg}$ swarf and scrap have been documented. However, as $\mathrm{Mg}$ is used as an alloying metal in conjunction with other metals such as aluminum (Al), most recycling efforts are focused on remelting scrap/swarf or electrolysis $[7,10]$. There is some work done on solid-state 
recycling of swarf/scrap material of metals such as $\mathrm{Al}$ and copper, with findings of energy savings and acceptable resulting material properties [9,11,12].

For $\mathrm{Mg}$ materials, previous work with solid-state recycling involved $\mathrm{Mg}$ alloys with methods such as rheo-diecasting (RDC) utilizing both primary alloy ingots and diecast scrap [13], blow-forming [14], extrusion of runner scrap [15] and turnings [16], as well as a study regarding the effect of recycled turning/chip sizes on the mechanical properties of the subsequent extruded Mg alloy [17].

While the resulting recycled $\mathrm{Mg}$ products from these studies show acceptable and even improved mechanical properties (especially with regards to tensile strength and in some cases, ductility), these solid-state recycling efforts only concerned $\mathrm{Mg}$ alloys and did not explore possibilities involving Mg nanocomposites or other novel materials. In addition, these prior efforts did not indicate plastic deformation on the recycled turnings as a factor in strengthening of the materials.

As the primary focus was on the feasibility and mechanical properties of solid-state recycled $\mathrm{Mg}$ scraps/turnings rather than systematic attempts at creating and optimizing a new processing method and its effects on a wider range of properties (such as ignition resistance, damping performance, etc.), the aforementioned works concerning recycling $\mathrm{Mg}$ alloy turnings also did not disclose the machining parameters used in generating the turnings.

These factors provided impetus for recent, systematic, and more comprehensive study involving direct utilization of the Mg-material turnings (which underwent plastic deformation in the process) according to documented, fixed machining parameters and cold-compressing them into billets, which were then hot-extruded in the same fashion as conventional machined billets. This was coined as the turning-induced deformation (TID) method and was applied not to just $\mathrm{Mg}$ alloys, but also to other lightweight $\mathrm{Mg}$ materials such as nanocomposites [18]. This paper summarizes the most recent works on $\mathrm{Mg}$ materials utilizing this method.

\section{TID Methodology}

As the generated turnings are obtained by localized plastic deformation on the $\mathrm{Mg}$ material surface arising from the cutting motion [19], the TID method, apart from its energy savings, also has potential to alter and improve the properties of $\mathrm{Mg}$ materials based on existing knowledge surrounding processing of $\mathrm{Mg}$ using severe plastic deformation (SPD) techniques $[17,20,21]$, where the extent of deformation during processing imparts superplastic properties on the material. Historically, this has been performed at higher temperatures such as the equal channel angular pressing (ECAP) process as well as at lower temperatures with the high-pressure torsion (HPT) method [22], thus providing a basis for TID as a new SPD method utilizing pre-deformed Mg materials (turnings) at lower temperatures as an extension of primary processing as seen in Figure 1 below: 


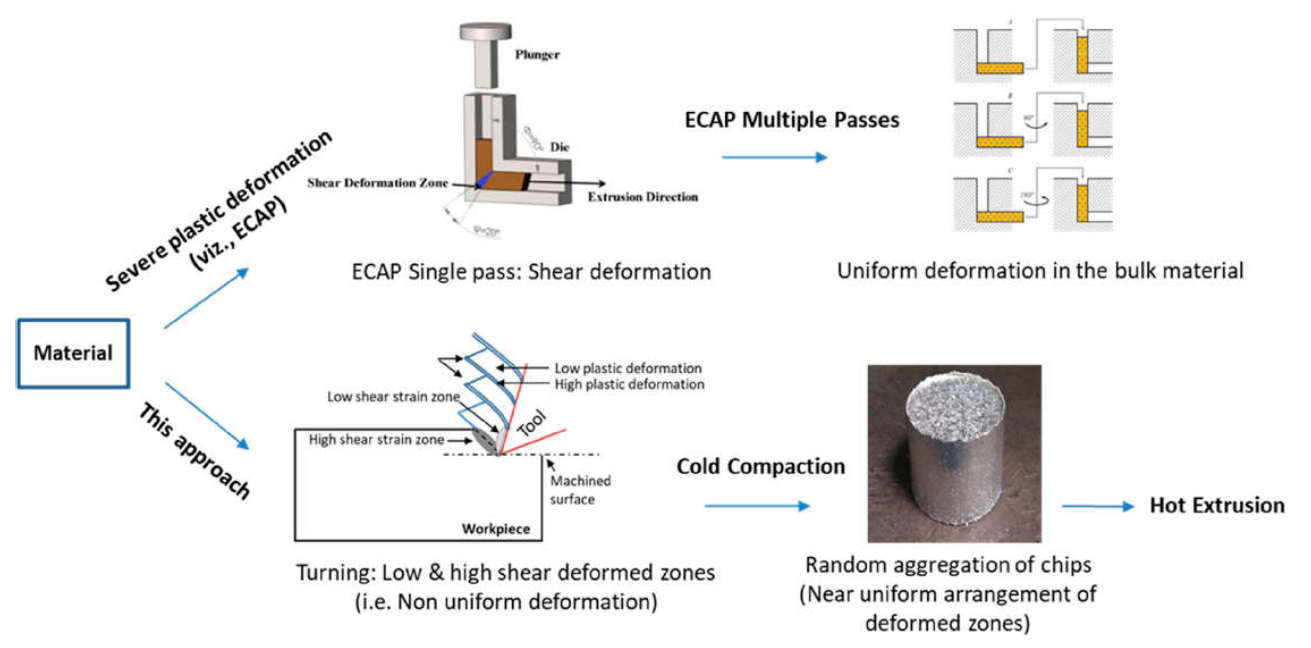

Figure 1. Comparison between ECAP as an existing SPD technique and the newly-explored TID processing method as a new SPD technique [18].

$\mathrm{Mg}$ materials in their bulk form are first cast into ingots using the disintegrated melt deposition method [23] to form the basis for this processing method. The resulting cast ingot then has its surfaces machined off to eliminate surficial contaminants. Turnings were then machined off the ingot using a lathe, which show apparent plastic deformation zones across the surfaces as in Figure 2 below:
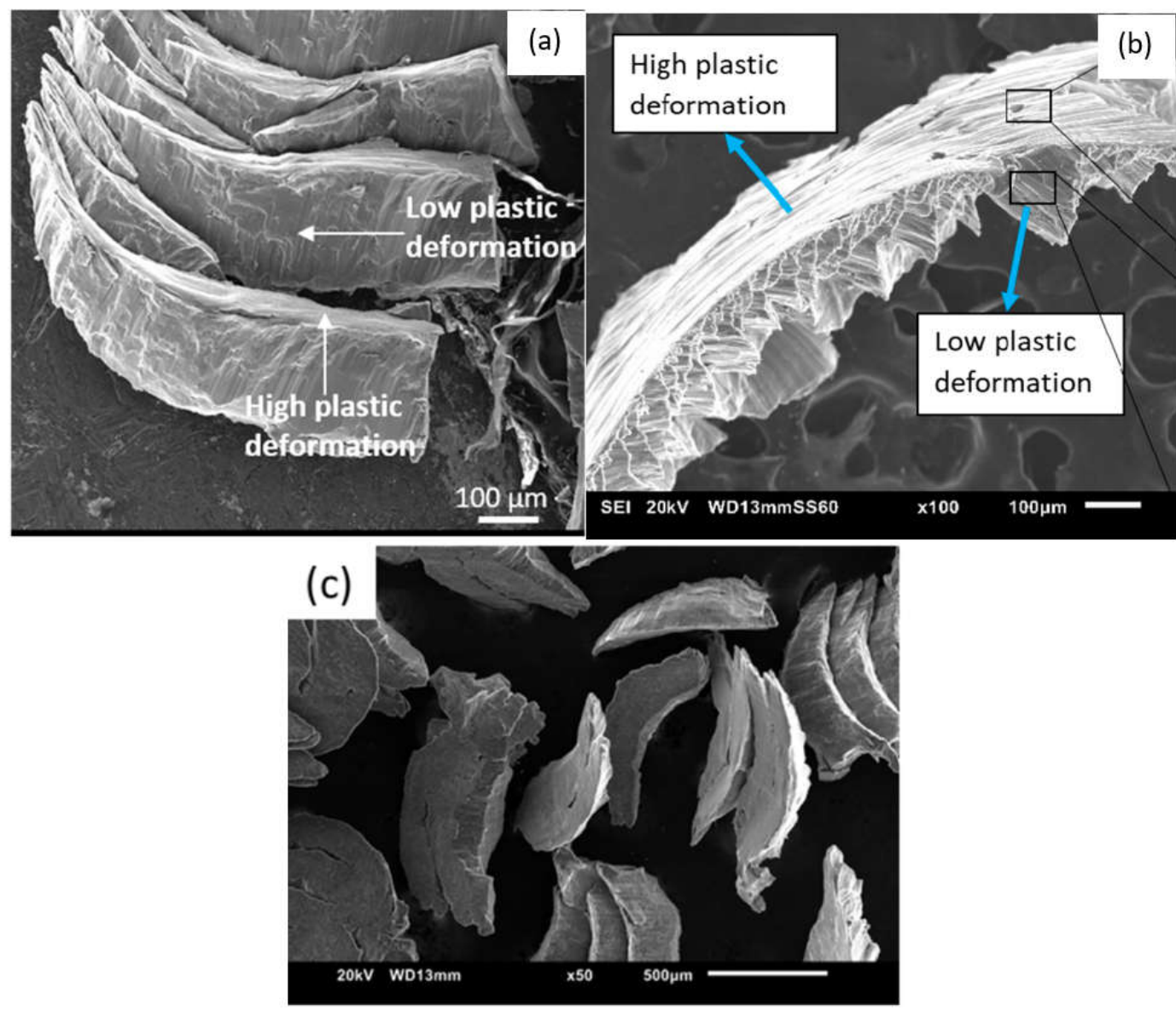

Figure 2. Micrographs of Mg-material turnings, showing plastic deformation zones for (a) $\mathrm{AZ91}$ alloy, (b) $\mathrm{Mg} / \mathrm{Fe}_{3} \mathrm{O}_{4}$ nanocomposites, and (c) ZK60 alloy. [18,24,25]. 
It is of note that in this case, dry machining was done to generate the turnings, owing to the excellent machinability of $\mathrm{Mg}$ [26], ensuring that no additional decontamination or separation steps were required during consolidation of turnings, thus increasing the economic viability of this processing method. The turnings were stored such that contamination and oxidation were minimized.

As the TID method is also intended to improve material properties, for any given material, parameters that may be adjusted such as depth of cut (DOC), cutting speed, and feed speed [27] are first selected, and kept constant for each set of turnings associated with each $\mathrm{Mg}$ material. Once sufficient loose turnings have been collected and gathered, they were then compressed into billets as in Figure 3 below:

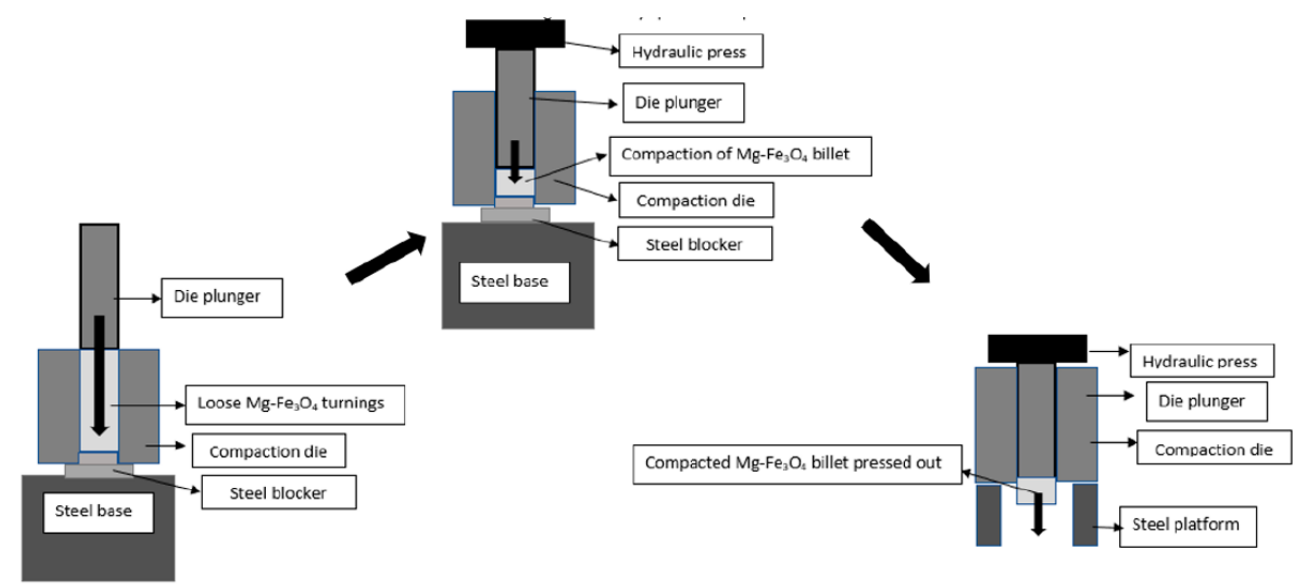

Loose turnings before compaction

Extraction of compacted billet

Figure 3. Schematic of turning compaction into TID billets [24].

The resulting compacted billets then undergo secondary processing (soaking for homogenization and hot extrusion) to obtain rods suitable for characterization, much in the same manner as with conventional machined billets. It should also be noted that the TID billets were synthesized without need for sintering, which further lowers the associated energy and production costs and thus increases the economic potential of this method.

For each material studied, conventional processing benchmarks were obtained by conventionally machining a billet from these ingots, followed by soaking and hot extrusion into sample rods under the same conditions as the TID billets. These sample rods were then also processed for characterization and quantification of material properties.

\section{Results}

Results and properties of Mg materials from previous works [18,24,25] concerning the TID method were consolidated and discussed in this review.

\subsection{TID Effect on Porosity}

As the TID method results in materials synthesized from compacted turnings, the resultant materials also had higher porosity than equivalent materials synthesized conventionally [12]. The increase in porosity due to the TID method is caused by presence of voids and pores within the resulting materials, consistent with findings in previous works related to recycling of Al turnings [12]. This can be mitigated by appropriate selection of machining parameters during turning generation, namely, with higher DOCs and lower cutting speeds, as seen in the following Table 1: 
Table 1. Density and porosity values of Mg materials undergoing both conventional and TID method processing [18,24,25].

\begin{tabular}{|c|c|c|c|c|}
\hline Material & Fabrication Method & Theoretical Density (g/cc) & Experimental Density (g/cc) & Porosity $(\%)$ \\
\hline AZ91_AR & Conventional & 1.835 & 1.816 & 1.06 \\
\hline AZ91_0.5DOC & TID (0.5 mm DOC) & 1.835 & 1.815 & 1.10 \\
\hline AZ91_1DOC & TID (1.0 mm DOC) & 1.835 & 1.812 & 1.27 \\
\hline AZ91_1.5DOC & TID (1.5 mm DOC) & 1.835 & 1.817 & 1.02 \\
\hline $\mathrm{Mg} / 1 \mathrm{Fe}_{3} \mathrm{O}_{4} \mathrm{DMD}$ & Conventional & 1.77 & $1.76 \pm 0.00$ & 0.56 \\
\hline $\mathrm{Mg} / 2 \mathrm{Fe}_{3} \mathrm{O}_{4} \mathrm{DMD}$ & Conventional & 1.81 & $1.78 \pm 0.01$ & 1.66 \\
\hline $\mathrm{Mg} / 3 \mathrm{Fe}_{3} \mathrm{O}_{4} \mathrm{DMD}$ & Conventional & 1.84 & $1.79 \pm 0.02$ & 2.72 \\
\hline $\mathrm{Mg} / 1 \mathrm{Fe}_{3} \mathrm{O}_{4}$ TID & $\begin{array}{l}\text { TID (one set of } \\
\text { parameters) }\end{array}$ & 1.77 & $1.75 \pm 0.01$ & 1.13 \\
\hline $\mathrm{Mg} / 2 \mathrm{Fe}_{3} \mathrm{O}_{4}$ TID & $\begin{array}{l}\text { TID (one set of } \\
\text { parameters) }\end{array}$ & 1.81 & $1.76 \pm 0.02$ & 2.76 \\
\hline $\mathrm{Mg} / 3 \mathrm{Fe}_{3} \mathrm{O}_{4} \mathrm{TID}$ & $\begin{array}{l}\text { TID (one set of } \\
\text { parameters) }\end{array}$ & 1.84 & $1.77 \pm 0.02$ & 3.81 \\
\hline ZK60_AR & Conventional & 1.83 & $1.825 \pm 0.002$ & 0.26 \\
\hline ZK60_HS & $\begin{array}{l}\text { TID (high cutting } \\
\text { speed) }\end{array}$ & 1.83 & $1.807 \pm 0.025$ & 1.23 \\
\hline ZK60_MS & $\begin{array}{l}\text { TID (medium cutting } \\
\text { speed) }\end{array}$ & 1.83 & $1.816 \pm 0.007$ & 0.77 \\
\hline ZK60_LS & TID (low cutting speed) & 1.83 & $1.822 \pm 0.005$ & 0.4 \\
\hline
\end{tabular}

\subsection{TID Effect on Ignition Resistance}

The resultant increase in porosity is linked with lower ignition temperature (and hence resistance) due to higher exposed material surface area for oxidation $[25,28]$. Hence the ignition temperatures of TID materials as measured using a thermo gravimetric analyzer (TGA) are generally lower with higher porosity compared to conventionally-processed $\mathrm{Mg}$ materials seen in Table 2 below:

Table 2. Ignition temperatures of Mg materials undergoing both conventional and TID method processing [24,25].

\begin{tabular}{ccc}
\hline Material & Fabrication Method & Ignition Temperature $\left({ }^{\circ} \mathbf{C}\right)$ \\
\hline $\mathrm{Mg} / 1 \mathrm{Fe}_{3} \mathrm{O}_{4} \mathrm{DMD}$ & Conventional & 630.6 \\
$\mathrm{Mg} / 2 \mathrm{Fe}_{3} \mathrm{O}_{4} \mathrm{DMD}$ & Conventional & 635.0 \\
$\mathrm{Mg} / 3 \mathrm{Fe}_{3} \mathrm{O}_{4} \mathrm{DMD}$ & Conventional & 635.2 \\
$\mathrm{Mg} / 1 \mathrm{Fe}_{3} \mathrm{O}_{4} \mathrm{TID}$ & TID (one set of parameters) & 625.4 \\
$\mathrm{Mg} / 2 \mathrm{Fe}_{3} \mathrm{O}_{4} \mathrm{TID}$ & TID (one set of parameters) & 633.1 \\
$\mathrm{Mg} / 3 \mathrm{Fe}_{3} \mathrm{O}_{4} \mathrm{TID}$ & TID (one set of parameters) & 632.2 \\
ZK60_AR & Conventional & 556 \\
ZK60_HS & TID (high cutting speed) & 521 \\
ZK60_MS & TID (medium cutting speed) & 528 \\
ZK60_LS & TID (low cutting speed) & 544 \\
\hline
\end{tabular}

As seen in Table 2 above, while the TID method does result in lower ignition temperature compared to conventionally-processed $\mathrm{Mg}$ materials, it is also seen that lower cutting speeds resulted in higher ignition temperatures, indicating that this parameter can be used to mitigate the adverse impact on ignition resistance.

\subsection{TID Effect on Damping Performance}

The increased porosity of the TID method has brought a benefit in terms of material damping performance; TID materials were found to have higher damping capacities as shown in Table 3 below. This is due to the presence of air gaps within the TID materials [29], and this effect has also been observed in works concerning porous magnesium materials [30,31] as well as spray-formed alloys [32]. It is also noted that for TID materials, no significant differences in elastic modulus were observed, indicating that the materials retained their stiffness, which is of importance in engineering/structural applications: 
Table 3. Damping capacities and elastic modulus of $\mathrm{Mg}$ materials undergoing both conventional and TID method processing [24,25].

\begin{tabular}{|c|c|c|c|}
\hline Material & Fabrication Method & $\begin{array}{c}\text { Damping Capacity } \\
\left(\times 10^{-6}\right)\end{array}$ & $\begin{array}{l}\text { Elastic Modulus } \\
\text { (GPa) }\end{array}$ \\
\hline $\mathrm{Mg} / 1 \mathrm{Fe}_{3} \mathrm{O}_{4} \mathrm{DMD}$ & Conventional & $410 \pm 48$ & 49.58 \\
\hline $\mathrm{Mg} / 2 \mathrm{Fe}_{3} \mathrm{O}_{4} \mathrm{DMD}$ & Conventional & $673 \pm 179$ & 46.92 \\
\hline $\mathrm{Mg} / 3 \mathrm{Fe}_{3} \mathrm{O}_{4} \mathrm{DMD}$ & Conventional & $1303 \pm 143$ & 46.05 \\
\hline $\mathrm{Mg} / 1 \mathrm{Fe}_{3} \mathrm{O}_{4} \mathrm{TID}$ & $\begin{array}{l}\text { TID (one set of } \\
\text { parameters) }\end{array}$ & $453 \pm 27$ & 48.70 \\
\hline $\mathrm{Mg} / 2 \mathrm{Fe}_{3} \mathrm{O}_{4}$ TID & $\begin{array}{l}\text { TID (one set of } \\
\text { parameters) }\end{array}$ & $690 \pm 22$ & 46.31 \\
\hline $\mathrm{Mg} / 3 \mathrm{Fe}_{3} \mathrm{O}_{4} \mathrm{TID}$ & $\begin{array}{l}\text { TID (one set of } \\
\text { parameters) }\end{array}$ & $1735 \pm 206$ & 46.85 \\
\hline ZK60_AR & Conventional & 99 & $47.78 \pm 0.29$ \\
\hline ZK60_HS & $\begin{array}{l}\text { TID (high cutting } \\
\text { speed) }\end{array}$ & 138 & $45.21 \pm 0.27$ \\
\hline ZK60_MS & $\begin{array}{l}\text { TID (medium cutting } \\
\text { speed) }\end{array}$ & 92 & $47.98 \pm 0.29$ \\
\hline ZK60_LS & $\begin{array}{l}\text { TID (low cutting } \\
\text { speed) }\end{array}$ & 145 & $46.89 \pm 0.28$ \\
\hline
\end{tabular}

It was observed that while the TID method led to better (higher) damping capacities as a whole, the lowest cutting speeds were found to result in $\mathrm{Mg}$ materials with the best overall damping properties, achieved with minimal differences to elastic modulus compared with conventionally-processed counterparts.

\subsection{TID Effect on Mechanical Strength}

TID-processed Mg materials have been observed to possess superior compressive and fracture strengths without compromising ductility. Considering the role of $\mathrm{Mg}$ as a structural metal in many engineering applications, increases in strength without compromising ductility (a well-known shortcoming of Mg) [33] using the TID method enables it to be used as a favorable pathway to generate superior $\mathrm{Mg}$ materials in the future as seen in Figure 4 and Table 4 below:

Table 4. Consolidated compressive properties associated with TID Mg materials and their improvement over conventionallyprocessed materials $[18,24,25]$.

\begin{tabular}{cccc}
\hline Material & Fabrication Method & $\mathbf{0 . 2 \%}$ Yield Strength (MPa) & Failure Strain (\%) \\
\hline AZ91_AR & Conventional & 207 & $20.3 \pm 1.3$ \\
AZ91_0.5DOC & TID (0.5 mm DOC) & 275 & $21.5 \pm 3.3$ \\
AZ91_1DOC & TID (1.0 mm DOC) & 309 & $20 \pm 2.0$ \\
AZ91_1.5DOC & TID (1.5 mm DOC) & 375 & $19 \pm 3.9$ \\
$\mathrm{Mg} / 1 \mathrm{Fe}_{3} \mathrm{O}_{4} \mathrm{DMD}$ & Conventional & 75 & 15.8 \\
$\mathrm{Mg} / 2 \mathrm{Fe}_{3} \mathrm{O}_{4} \mathrm{DMD}$ & Conventional & 100 & 16.9 \\
$\mathrm{Mg} / 3 \mathrm{Fe}_{3} \mathrm{O}_{4} \mathrm{DMD}$ & Conventional & 76 & 18.9 \\
$\mathrm{Mg} / 1 \mathrm{Fe}_{3} \mathrm{O}_{4} \mathrm{TID}$ & TID (one set of parameters) & 99 & 18.2 \\
$\mathrm{Mg} / 2 \mathrm{Fe}_{3} \mathrm{O}_{4} \mathrm{TID}$ & TID (one set of parameters) & 111 & 18.4 \\
$\mathrm{Mg} / 3 \mathrm{Fe}_{3} \mathrm{O}_{4}$ TID & TID (one set of parameters) & 91 & 19.1 \\
ZK60_AR & Conventional & $284 \pm 3$ & $20 \pm 0.2$ \\
ZK60_HS & TID (high cutting speed) & $257 \pm 1$ & $20 \pm 1.4$ \\
ZK60_MS & TID (medium cutting speed) & $299 \pm 26$ & $22 \pm 1$ \\
ZK60_LS & TID (low cutting speed) & $319 \pm 3$ & $21 \pm 3$ \\
\hline
\end{tabular}




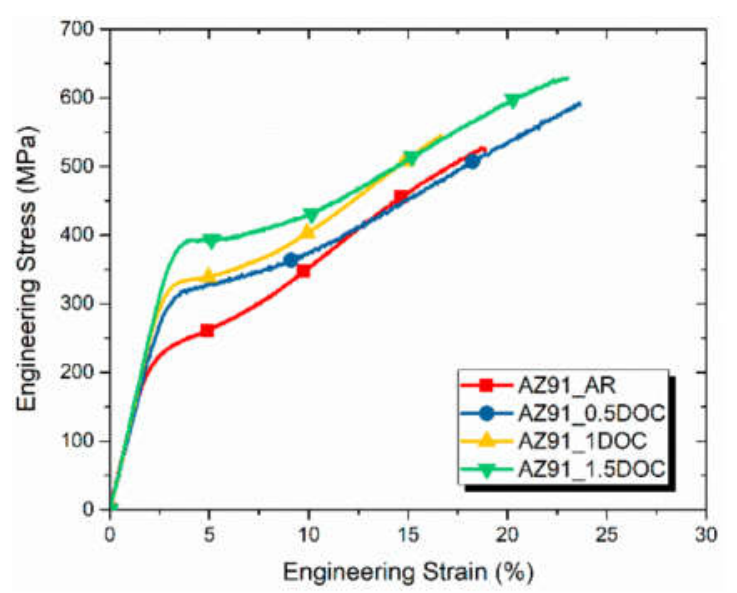

(a)

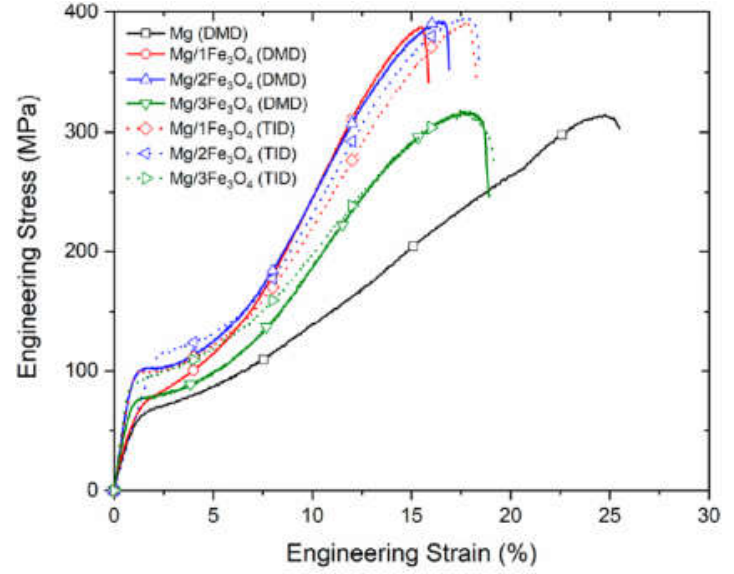

(b)

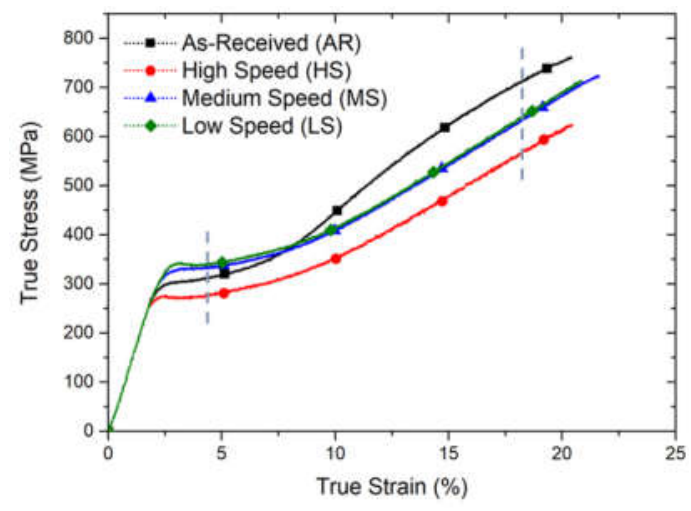

(c)

Figure 4. Compressive stress-strain charts associated with TID Mg materials and their improvement over conventionallyprocessed materials for (a) AZ91 alloy, (b) $\mathrm{Mg} / \mathrm{Fe}_{3} \mathrm{O}_{4}$ nanocomposites, and (c) ZK60 alloy [18,24,25].

As seen in the Figure 4 and Table 4 above, the TID method has positive influence on the yield strengths of all Mg materials. Notably, for Mg alloys, highest DOCs and lowest cutting speeds were observed to result in $\mathrm{Mg}$ materials with the best yield strength, while maintaining the ductility levels associated with the as-received (conventionally-processed) samples. For $\mathrm{Mg}$ nanocomposites, while the study was a direct comparison between conventional machining and the TID method with only one set of TID parameters, the TID method resulted in not only improved strength, but also improved ductility with higher failure strains. Such improvements without compromise in ductility thus provide justification for this method in producing Mg materials with superior strengths.

To an extent, these findings align with previous observations involving solid-state recycling of Mg materials, both from scraps as well as machine turnings [14-17] as they exhibit higher mechanical (tensile) strength than conventionally-processed materials. However, with regards to (tensile) ductility, previous efforts involving machine turnings report inferior ductility compared to conventionally-processed counterparts [14,17], citing excessive oxide presence due to contamination as the cause.

Considering that recent TID efforts specifically stored $\mathrm{Mg}$ turnings in such a manner as to avoid contamination and oxidation [24,25], and the knowledge that oxide size affects ductility [18], this can explain the difference in reported ductility levels and thus overall material performance.

It was also reported that increases in mechanical strength could be attributed to dispersion of oxide particles from turning surfaces [34], but in absence of a comprehensive 
study concerning the effects of oxide particle presence and dispersion on mechanical strength within recycled $\mathrm{Mg}$ materials, a definitive conclusion cannot yet be made.

\subsection{TID Effect on Microhardness}

Another mechanical property positively affected by the TID method is the microhardness. Unlike yield strength, as previously elaborated, this is an indicator of local mechanical behavior of the material. Table 5 below shows the microhardness values of Mg alloys:

Table 5. Average microhardness of Mg materials undergoing both conventional and TID method processing $[18,25]$.

\begin{tabular}{ccc}
\hline Material & Fabrication Method & Microhardness (HV) \\
\hline AZ91_AR & Conventional & $155 \pm 7$ \\
AZ91_0.5DOC & TID $(0.5$ mm DOC) & $157 \pm 9$ \\
AZ91_1DOC & TID (1.0 mm DOC) & $166 \pm 5$ \\
AZ91_1.5DOC & TID (1.5 mm DOC) & $185 \pm 3$ \\
ZK60_AR & Conventional & $136 \pm 7$ \\
ZK60_HS & TID (high cutting speed) & $141 \pm 6$ \\
ZK60_MS & TID (medium cutting speed) & $151 \pm 9$ \\
ZK60_LS & TID (low cutting speed) & $157 \pm 2$ \\
\hline
\end{tabular}

The increased microhardness of TID materials relative to conventionally-processed counterparts conform with prior efforts involving severe plastic deformation processing methods of Mg materials [21], indicating that the TID method was effective in imparting superior microhardness.

With regards to Mg alloys fabricated by the TID method, as with the previous compressive strength observed previously, once again highest DOCs and lowest cutting speeds produced $\mathrm{Mg}$ alloys with the highest microhardness values.

\subsection{TID Effect on Grain Size}

Furthermore, with regards to grain size, the hot extrusion performed on the Mg materials also allows for dynamic recrystallization to occur, resulting in finer (smaller) average grain sizes [35-37]. Previous TID method studies on Mg materials (alloys and nanocomposites) have further reduced the grain sizes compared to conventionally-processed $\mathrm{Mg}$ materials undergoing the same hot extrusion process, as in Table 6 below:

Table 6. Average grain sizes of Mg materials undergoing both conventional and TID method processing $[18,24,25]$.

\begin{tabular}{ccc}
\hline Material & Fabrication Method & Average Grain Size $(\mu \mathrm{m})$ \\
\hline AZ91_AR & Conventional & $3.17 \pm 0.86$ \\
AZ91_0.5DOC & TID $(0.5$ mm DOC) & $1.82 \pm 0.44$ \\
AZ91_1DOC & TID $(1.0$ mm DOC) & $1.54 \pm 0.43$ \\
AZ91_1.5DOC & TID $(1.5$ mm DOC) & $1.27 \pm 0.34$ \\
$\mathrm{Mg} / 1 \mathrm{Fe}_{3} \mathrm{O}_{4} \mathrm{DMD}$ & Conventional & $16 \pm 6$ \\
$\mathrm{Mg} / 2 \mathrm{Fe}_{3} \mathrm{O}_{4} \mathrm{DMD}$ & Conventional & $8 \pm 3$ \\
$\mathrm{Mg} / 3 \mathrm{Fe}_{3} \mathrm{O}_{4} \mathrm{DMD}$ & Conventional & $10 \pm 4$ \\
$\mathrm{Mg} / 1 \mathrm{Fe}_{3} \mathrm{O}_{4} \mathrm{TID}$ & TID (one set of parameters) & $8 \pm 2$ \\
$\mathrm{Mg} / 2 \mathrm{Fe}_{3} \mathrm{O}_{4} \mathrm{TID}$ & TID (one set of parameters) & $8 \pm 3$ \\
$\mathrm{Mg} / 3 \mathrm{Fe}_{3} \mathrm{O}_{4} \mathrm{TID}$ & TID (one set of parameters) & $9 \pm 3$ \\
ZK60_AR & Conventional & $0.99 \pm 0.47$ \\
ZK60_HS & TID (high cutting speed) & $1.13 \pm 0.45$ \\
ZK60_MS & TID (medium cutting speed) & $1.05 \pm 0.29$ \\
ZK60_LS & TID (low cutting speed) & $0.89 \pm 0.25$ \\
\hline
\end{tabular}

Comparing the findings in Figure 4 and Tables 4-6 above, the smaller grains contribute to multiple desirable outcomes such as grain hardening [38] and higher hardness. The 
smaller average grain sizes also correlate with increasing mechanical strength according to the Hall-Petch relationship [39] due to the greater amounts of grain boundary area, increasing the barriers to dislocation propagation [40].

This is also in line with other studies concerning Mg materials which underwent prior deformation including severe plastic deformation as with ECAP and HPT [21,22], uniaxial compaction $[17,28]$, and efforts regarding solid-state recycling of $\mathrm{Mg}$ turnings [14-17] exhibiting smaller average grain sizes and higher mechanical strength. Thus, this is yet another finding in favor of TID as a Mg-material processing method.

Within the TID method itself, for Mg alloys highest DOCs and lowest cutting speeds resulted in the finest grain sizes. As for nanocomposites, available work focused on only one set of machining parameters. However, the TID method resulted in markedly finer grains as compared to conventionally-processed nanocomposites. This finding explains the previous observed correlation between machining parameters (highest DOCs and lowest cutting speeds) with superior mechanical properties.

\section{Conclusions}

Based on published work thus far concerning the TID method, the following conclusions have been observed:

1. Turnings generated from machining were viable for direct utilization in further processing to billets, thus increasing the proportion of material utilized following primary processing (casting) relative to conventional processing methods where material beyond specified dimensions is normally machined off and discarded. In addition, this was achieved without use of sintering, resulting in a processing method that confers energy savings as well as reducing Mg-material waste and requirements for a given production volume.

2. The TID method consistently produced materials possessing superior properties to that of conventionally processed materials with minimal compromises, opening up the path to synthesis of superior Mg materials. Notably, increased mechanical strength, ductility, microhardness, and damping performance were observed with only minimal compromises in porosity and ignition resistance.

3. Machining parameters such as higher DOCs and lower cutting speeds have produced Mg materials with the most desirable properties including low porosity, higher ignition resistance, finer grains, higher mechanical strength and microhardness, as well as damping capacities without significant compromises in ductility, providing a basis for further studies on parameter adjustment and effects on outcomes of TID-processed materials.

These findings show that the TID method is a favorable pathway to synthesis and recycling of $\mathrm{Mg}$ materials and is feasible as a basis on which further work on using the TID method may continue. Further work in this field will contribute towards more optimization in terms of economic benefits as well as the pursuit of ever-better $\mathrm{Mg}$ materials.

Author Contributions: Conceptualization, M.G.; formal analysis, M.J.; investigation, M.J.; writingoriginal draft preparation, M.J.; writing-review and editing, M.J. and M.G.; supervision, M.G.; All authors have read and agreed to the published version of the manuscript.

Funding: This research was funded by MINISTRY OF EDUCATION, SINGAPORE Tier 1, grant number R-265-000-684-114.

Conflicts of Interest: The authors declare no conflict of interest.

\section{References}

1. Cao, H.; Pistidda, C.; Riglos, M.V.C.; Chaudhary, A.-L.; Capurso, G.; Tseng, J.-C.; Puszkiel, J.; Wharmby, M.T.; Gemming, T.; Chen, P.; et al. Conversion of magnesium waste into a complex magnesium hydride system: $\mathrm{Mg}(\mathrm{NH} 2) 2-\mathrm{LiH}$. Sustain. Energy Fuels 2020, 4, 1915-1923. [CrossRef]

2. Maier, P.; Hort, N. Magnesium Alloys for Biomedical Applications. Metals 2020, 10, 1328. [CrossRef]

3. Akyuz, B. Machinability of Magnesium and Its Alloys. TOJSAT Online J. Sci. Technol. 2011, 1, 31-38. 
4. Blawert, N.H.C.; Kainer, K.U. Automotive Application of Magnesium and Its Alloys. Trans. Indian Inst. Met. 2004, 57, 397-408.

5. Lapovok, R.Y.; Thomson, P.F. Production of dense rod from magnesium swarf for re-melting. Magnes. Technol. 2004, 1, 149-154.

6. Bell, R.W.N.; Parker, D.; Baker, K.; Lee, P.; Magnesium Recycling in the EU. Oakdene Hollins. 7 June 2017. Available online: https://cdn.ymaws.com/www.intlmag.org/resource/resmgr/sustainability/FullRprt_EU-Mg-recycling_201.pdf (accessed on 13 August 2021).

7. Ditze; Scharf, C. Recycling of Magnesium Alloys. In Magnesium-Alloys and Technology; Wiley Online Books: Hoboken, NJ, USA, 2003; pp. 254-278.

8. Survey, U.S.G. Mineral Commodity Summaries 2021. In Mineral Commodity Summaries; Reston, V.A., Ed.; Report; 2021. Available online: http:/ / pubs.er.usgs.gov/publication/mcs2021 (accessed on 13 August 2021).

9. Shamsudin, S.; Lajis, M.A.; Zhong, Z.W. Solid-state recycling of light metals: A review. Adv. Mech. Eng. 2016, 8, 1687814016661921. [CrossRef]

10. Powell IV, A.C.; Pati, S.; Derezinski, S.; Strauss, J.; Pal, U.; Zink, P.; Guan, X. Efficient One-Step Electrolytic Recycling of LowGrade and Post-Consumer Magnesium Scrap. Metal Oxygen Separation Technologies, Inc., 19 July 2012. Available online: https: / / www.osti.gov/servlets / purl/1046980 (accessed on 13 August 2021).

11. Galanty, M.; Kazanowski, P.; Kansuwan, P.; Misiolek, W.Z. Consolidation of metal powders during the extrusion process. J. Mater. Process. Technol. 2002, 125-126, 491-496. [CrossRef]

12. Chiba, R.; Yoshimura, M. Solid-state recycling of aluminium alloy swarf into c-channel by hot extrusion. J. Manuf. Process. 2015, 17, 1-8. [CrossRef]

13. Liu, G.; Wang, Y.; Fan, Z. A physical approach to the direct recycling of Mg-alloy scrap by the rheo-diecasting process. Mater. Sci. Eng. A 2008, 472, 251-257. [CrossRef]

14. Chino, Y.; Kobata, M.; Shimojima, K.; Hosokawa, H.; Yamada, Y.; Iwasaki, H.; Mabuchi, M. Blow Forming of Mg Alloy Recycled by Solid-State Recycling. Mater. Trans. 2004, 45, 361-364. [CrossRef]

15. Chino, Y.; Jae-Seol, L.; Nakaura, Y.; Ohori, K.; Mabuchi, M. Mechanical Properties of Mg-Al-Ca Alloy Recycled by Solid-State Recycling. Mater. Trans. 2005, 46, 2592-2595. [CrossRef]

16. Mabuchi, M.; Kubota, K.; Higashi, K. New Recycling Process by Extrusion for Machined Chips of AZ91 Magnesium and Mechanical Properties of Extruded Bars. Mater. Trans. JIM 1995, 36, 1249-1254. [CrossRef]

17. Wu, S.; Ji, Z.; Zhang, T. Microstructure and mechanical properties of AZ31B magnesium alloy recycled by solid-state process from different size chips. J. Mater. Process. Technol. 2009, 209, 5319-5324. [CrossRef]

18. Tekumalla, S.; Ajjarapu, M.; Gupta, M. A Novel Turning-Induced-Deformation Based Technique to Process Magnesium Alloys. Metals 2019, 9, 841. [CrossRef]

19. Ghadbeigi, H.; Bradbury, S.R.; Pinna, C.; Yates, J.R. Determination of micro-scale plastic strain caused by orthogonal cutting. Int. J. Mach. Tools Manuf. 2008, 48, 228-235. [CrossRef]

20. Lapovok, R.; Estrin, Y. 4-Superplasticity in magnesium alloys by severe plastic deformation. In Advances in Wrought Magnesium Alloys; Bettles, C., Barnett, M., Eds.; Woodhead Publishing: Cambridge, UK, 2012; pp. 144-185.

21. Yuan, Y.; Ma, A.; Jiang, J.; Lu, F.; Jian, W.; Song, D.; Zhu, Y.T. Optimizing the strength and ductility of AZ91 Mg alloy by ECAP and subsequent aging. Mater. Sci. Eng. A 2013, 588, 329-334. [CrossRef]

22. Al-Zubaydi, A.S.J.; Zhilyaev, A.P.; Wang, S.C.; Reed, P.A.S. Superplastic behaviour of AZ91 magnesium alloy processed by high-pressure torsion. Mater. Sci. Eng. A 2015, 637, 1-11. [CrossRef]

23. Rao, K.; Suresh, K.; Prasad, Y.; Hort, N.; Gupta, M. Enhancement of Strength and Hot Workability of AZX312 Magnesium Alloy by Disintegrated Melt Deposition (DMD) Processing in Contrast to Permanent Mold Casting. Metals 2018, 8, 437. [CrossRef]

24. Johanes, M.; Tekumalla, S.; Gupta, M. Fe3O4 Nanoparticle-Reinforced Magnesium Nanocomposites Processed via Disintegrated Melt Deposition and Turning-Induced Deformation Techniques. Metals 2019, 9, 1225. [CrossRef]

25. Tekumalla, S.; Gupta, N.; Gupta, M. Influence of turning speed on the microstructure and properties of magnesium ZK60 alloy pre-processed via turning-induced-deformation. J. Alloy. Compd. 2020, 831, 154840. [CrossRef]

26. Guo, Y.; Salahshoor, M. Process mechanics and surface integrity by high-speed dry milling of biodegradable magnesium-calcium implant alloys. CIRP Ann. 2010, 59, 151-154. [CrossRef]

27. Gugulothu, B.; Kumsa, D.K.; Kassa, M.B. Effect of process parameters on centre lathe of EN8 steel in turning process. Mater. Today Proc. 2020, 46, 228-233. [CrossRef]

28. Tekumalla, S.; Chun, L.S.; Gupta, M. Preprocessing of powder to enhance mechanical and thermal response of bulk magnesium. Met. Powder Rep. 2019, 74, 137-140. [CrossRef]

29. Atlas Foundry Company. Mechanical Properties of Gray Iron-Damping Capacity. Available online: http://www.atlasfdry.com/ grayiron-damping.htm (accessed on 6 August 2021).

30. Li, Q.; Jiang, G.; Dong, J.; Hou, J.; He, G. Damping behavior and energy absorption capability of porous magnesium. J. Alloy. Compd. 2016, 680, 522-530. [CrossRef]

31. Xie, Z.-K.; Tane, M.; Hyun, S.-K.; Okuda, Y.; Nakajima, H. Vibration-damping capacity of lotus-type porous magnesium. Mater. Sci. Eng. A 2006, 417, 129-133. [CrossRef]

32. Li, B.; Lavernia, E.J. Spray Forming of MMCs. In Comprehensive Composite Materials, 1st ed.; Kelly, A., Zweben, C., Eds.; Online; Elsevier: Amsterdam, The Netherlands, 2000; Volume 3, pp. 617-653. 
33. Gupta, M.; Wong, W.L.E. Magnesium-based nanocomposites: Lightweight materials of the future. Mater. Charact. 2015, 105, 30-46. [CrossRef]

34. Tekumalla, S.; Shabadi, R.; Yang, C.; Seetharaman, S.; Gupta, M. Strengthening due to the in-situ evolution of $11^{\prime}$ Mg-Zn rich phase in a ZnO nanoparticles introduced Mg-Y alloy. Scr. Mater. 2017, 133, 29-32. [CrossRef]

35. Tekumalla, S.; Yang, C.; Seetharaman, S.; Wong, W.L.E.; Goh, C.S.; Shabadi, R.; Gupta, M. Enhancing overall static/dynamic/damping/ignition response of magnesium through the addition of lower amounts (<2\%) of yttrium. J. Alloy. Compd. 2016, 689, 350-358. [CrossRef]

36. Kim, S.-H.; Lee, S.W.; Moon, B.G.; Kim, H.S.; Kim, Y.M.; Park, S.H. Influence of extrusion temperature on dynamic deformation behaviors and mechanical properties of Mg-8Al-0.5Zn-0.2Mn-0.3Ca-0.2Y alloy. J. Mater. Res. Technol. 2019, 8, 5254-5270. [CrossRef]

37. Stanford, N. Micro-alloying Mg with $\mathrm{Y}, \mathrm{Ce}, \mathrm{Gd}$ and La for texture modification-A comparative study. Mater. Sci. Eng. A 2010, 527, 2669-2677. [CrossRef]

38. Yu, H.; Xin, Y.; Wang, M.; Liu, Q. Hall-Petch relationship in Mg alloys: A review. J. Mater. Sci. Technol. 2018, 34, 248-256. [CrossRef]

39. Yang, W.; Tekumalla, S.; Gupta, M. Cumulative Effect of Strength Enhancer—Lanthanum and Ductility Enhancer-Cerium on Mechanical Response of Magnesium. Metals 2017, 7, 241. [CrossRef]

40. Brush Wellman, Inc. Grain Size and Material Strength. In Technical Tidbits; Brush Wellman, Inc.: Mayfield Heights, OH, USA, 2010. 